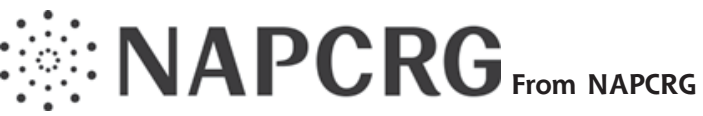

Ann Fam Med 2021;19:568-569. https://doi.org/10.1370/afm.2753

\section{FROM NAPCRG: FOURTH INTERNATIONAL CONFERENCE ON PRACTICE FACILITATION}

\section{ICPF Focuses on Advancing Facilitation in Light of Pandemics, Health Systems Change, and Inequities}

Attendees met virtually August 5-6, 2021 for the 4th International Conference on Practice Facilitation (ICPF). With continued support from the Agency for Healthcare Research and Quality (AHRQ) and the North American Primary Care Research Group (NAPCRG), the ICPF aims to recognize and address the needs of the professional community of practice facilitators ( $\mathrm{PFs}$ ) by advancing the science and best practices of facilitation.

The 85 registrants included PFs, program managers, and scientists from the United States and Canada; over one-half were first-time attendees. Building on our successful prior in-person conferences in 2017, 2018, ${ }^{2}$ and $2019{ }^{3}$ we engaged the community to design and deliver a virtual conference that capitalized on interactive technologies to provide relevant and engaging content. This conference focused on "Growing Practice Facilitation against the Odds," particularly innovations in response to pandemics, health care system changes, and inequities. The program included peerreviewed poster abstracts plus invited presentations on: (1) Developing Best Practices and Resources, (2) Practice Facilitator Training and Ongoing Development, (3) Practice Facilitator Skill Building, (4) Sustaining and Managing Practice Facilitation Programs, (5) Advancing the Science, and (6) Leveraging Technology.

The day 1 plenary "Using Facilitation to Promote Health Equity: Preliminary Thoughts on an Explicit Shift" was led by Eva Woodward, PhD from the Veterans Administration (VA) Center for Mental Healthcare and Outcomes Research Center for Health Services Research at University of Arkansas, who provided practical frameworks and skills to attend to health equity in improvement work. Other sessions addressed facilitation for new and emerging PFs, advanced practice facilitation strategies, adapting facilitation in light of 2020 challenges, and a virtual lounge and poster walk. The poster winner was Benjamin Webel, John Fune, Alison Huffstetler, Michelle Rockwell, Alex Krist, Roy Sabo for "Pivoting to Virtual Practice Facilitation."

The day 2 plenary on "Strategies and Best Practices in Virtual Facilitation" was moderated by Ann Romer,
MS from OCHIN and included panelists Meg Bowen, BA, Oyinkansola Ogunrinde, MHSA, and Molly Volk, MHS from OCHIN $;$ Dr Katherine M. Dollar at the VA Center for Integrated Healthcare; and Shannon Peaden, MBA from the Eastern AHEC. Other session topics included relationship development and resource sharing ${ }_{i}$ clinic engagement through critical juncture, goal-oriented practice facilitation; and using reflective writing. The closing session was a look back and a look ahead to chart a path forward for practice facilitation, and included a presentation by strategic illustrator, Kriss Wittmann, who captured key messages from conference discussions in visual representations. Plenary presentation videos and graphic artist representations are available on the NAPCRG website.

Post-conference evaluations from nearly one-half of the registrants $(47 \%)$ demonstrated high levels of satisfaction with conference content. Participants' reflections on the most valuable aspect highlighted "opportunities for questions," "excellent interactive sessions," and "the chat and ability to interact with other attendees." This suggests that conference quality was maintained even on a virtual platform. Evaluation feedback reinforced the value of "hearing others' experiences - it solidified thinking on how to integrate in my practice," and the importance of being exposed to "...challenges others have had and how they overcame them."

The ICPF provides a venue that encourages professional networking and skills to develop leaders in the application, management, and study of practice facilitation. Through the PF Learning Community, ICPF participants will continue to shape the development of this health care profession. As one attendee "chatted:" "This is the most applicable conference I have ever been to. I appreciate hearing from so many doing such similar work!"

On behalf of the ICPF Steering Committee, we invite you to stay tuned for upcoming news and opportunities related to promoting the field of practice facilitation!

Zsolt Nagykaldi, $P b D_{i}$ Melinda M. Davis, PbD, Paula Darby Lipman, $\mathrm{PbD}$, Leanora Dluzak, MA, Leyla Haddad, $M B A_{i}$ On bebalf of the ICPF Steering Committee

\section{References}

1. Davis M, Nagykaldi Z, Lipman PD, Haught J \& ICPF Steering Committee. First International Conference on Practice Facilitation: a success! Ann Fam Med. 2018;16(3):274-275. 10.1370/afm.2252

2. Nagykaldi Z, Davis MM, Lipman PD, Dluzak L, Haught J, \& ICPF Steering Committee. Second International Conference on Practice Facilitation (ICPF) focuses on building capacity. Ann Fam Med. 2019; 17(3):276-277. 10.1370/afm.2404

3. Nagykaldi Z, Davis MM, Lipman PD, Dluzak L, Haught J. Third International Conference on Practice Facilitation (ICPF) focuses on extending facilitation to the community. Ann Fam Med. 2020;18(1): 89-90. 10.1370/afm.2507 